\title{
Dibenzo-tetraphenyl diindeno as hole transport layer for perovskite solar cells fabrication
}

Meenakshi Pegu a , Laura Caliò ${ }^{\text {c\# }}$, Mehrad Ahmadpour ${ }^{\text {d }}$, Horst-Günter Rubahn ${ }^{\text {d }}$, Samrana Kazim, ${ }^{\text {a,b }}$ Morten Madsen ${ }^{\mathrm{d}}$ and Shahzada Ahmad ${ }^{\mathrm{a}, \mathrm{b}^{*}}$

${ }^{a}$ BCMaterials, Basque Center for Materials, Applications and Nanostructures, Bld. Martina Casiano, UPV/EHU Science Park, Barrio Sarriena s/n, 48940 Leioa, Spain Tel: +34 946128811

Email:shahzada.ahmad@bcmaterials.net

' IKERBASQUE, Basque Foundation for Science, Bilbao, 48013, Spain

${ }^{\mathrm{c} A b e n g o a}$ Research, Abengoa, C/ Energia Solar n ${ }^{\mathrm{O}}$, Campus Palmas Altas-41014, Sevilla, Spain

${ }^{\mathrm{d} S D U}$ NanoSYD, Mads Clausen Institute, University of Southern Denmark, Alsion 2, 6400 Sønderborg

\#Present Address: Instituto de Ciencia de Materiales de Sevilla, c/Americo Vespucio 41092 Sevilla, Spain

\section{Abstract:}

Semi-transparent perovskite solar cells have the competitive edge of being employed for building integrated photovoltaics due to their aesthetic benefits as light harvesting windows / facades. Perovskites have received considerable attention in recent years as a thin film photovoltaic alternative, that can also be tweaked for its transparency, evolving from potentially high bandgaps that are suited for semi-transparent solar cell fabrication. Due to the existing trade of between the efficiency and transparency of a perovskite solar cell, tuning the band gap can address this by making a bridge between the aforementioned parameters. We report our findings on the use of a wide-bandgap perovskite $\mathrm{MAPbBr}_{3}$, with a rational energetic level hole transport materials based on polycyclic aromatic hydrocarbon molecules that can be a promising alternative class of p-type material. In the present work, DBP (Dibenzo $\left\{\left[\mathrm{f}, \mathrm{f}^{\prime}\right]-4,4^{\prime}, 7,7^{\prime}\right.$-tetraphenyl $\}$ diindeno[1,2,3-cd :1',2',3'-lm]perylene, was evaluated with high band gap as well as with $\left(\mathrm{FAPbI}_{3}\right)_{0.85}\left(\mathrm{MAPbBr}_{3}\right)_{0.15}$ perovskites for the fabrication of solar cell. DBP based solar cells yielded competitive power conversion efficiencies as compared to classical HTMs.

Keywords: Solar cells, Perovskite solar cells, charge transfer, DBP, hole transport materials 


\section{Introduction:}

Recently developed metal halide perovskites [1,2] has generated a significant interest in the photovoltaic (PV) field and the current decade has witness notable progress in its investigation. Such perovskites can be expressed as $\mathrm{ABX}_{3}$, where A stands for organic or inorganic metal cation, $\mathrm{B}$ is a metal ion and $\mathrm{X}$ is an anion which is generally halide [3-5]. The bromide based hybrid perovskites, in particular, are intriguing due to their large band gap of 2.2-2.4 eV that also allows them to serves as a top layer for dual-junction tandem solar cells with crystalline $\mathrm{Si}$, or copper indium gallium diselenide (CIGS) [6-8]. Bromide based perovskites exhibits high absorption coefficient, furthermore are relatively stable against humidity and moisture to yield higher device lifetimes [9-11]. Reducing the active layer thickness only is not a viable route for obtaining semitransparent solar cells, as it may come along with significant drops in device performance [12]. The possibility of tweaking the absorption range by means of employing high bandgap materials to regulate the absorption can be an ideal approach, which may also be highly suitable for tandem based devices.

Methylammonium lead bromide $\left(\mathrm{MAPbBr}_{3}\right)$ were first implemented as sensitizers for titania scaffold in a liquid junction solar cells $[13,14]$. The substitution of the bromine in the perovskite decreases the ionic size and thus alter the optical band gap, i.e. $E_{\mathrm{g}}$ of $\mathrm{MAPbBr}_{3} 2.24 \mathrm{eV}$ for single crystal and $2.32 \mathrm{eV}$ for the polycrystalline films, yielding higher voltage potential in the devices. Using the crystallization controlled spin coating process the maximum efficiency of 10.4 $\%$ has been achieved via the solution deposition method [15]. Mesoporous $\mathrm{TiO}_{2}$ based devices using $\mathrm{MAPbBr}_{3}$ via one-step solution deposition process as light harvester was fabricated with an open circuit voltage of up to $1.3 \mathrm{~V} . \mathrm{MAPbBr}_{3}$ shows strong absorption at around $375 \mathrm{~nm}$ and the photoluminescence emission of the film with an intense and narrow peak can be observed at around 
slightly red-shifted position at $543 \mathrm{~nm}$ [16]. By optimizing deposition conditions [17], solar cells based on formamidinium bromide-based was reported $[18,19]$. A maximum PCE of $10.61 \%$ was reported by Zhang et al, followed by $8.2 \%$ PCE by Arora et al., $\mathrm{FAPbBr}_{3}$ has a narrow band gap of $2.23 \mathrm{eV}$ as compared to MA-based perovskites $(2.32 \mathrm{eV})$ for the polycrystalline films [20,21]. The UV-vis absorbance peak for $\mathrm{FAPbBr}_{3}$ appears at $532 \mathrm{~nm}$ whereas the photoluminescence peak was observed at 550nm. Improved thermal stability of $\mathrm{FAPbBr}_{3}$ was reported by annealing the films at $150^{\circ} \mathrm{C}$ for 60 minutes $[19,22]$. The classical HTM such as Spiro-OMeTAD are not suitable in combination with high band gap perovskites, mainly due to its energetic level mismatch. Polycyclic aromatic hydrocarbons (PAHs) are a class of organic molecules that has received significant attention due to their semiconducting applications in organic electronics and structural interests of well-defined graphene segments. Mullen et.al reported synthetic methodologies towards the development of pi extended PAHs that allow achieving high efficiency and functionality $[23,24]$. Similarly graphene has been studied extensively as a potential material for organic electronics and semiconductors [25]. Efforts are being made to develop a class of PAHs that boost the semiconducting properties by developing pi-conjugated $\mathrm{sp}^{2}$ hydrocarbon based molecules by functionalization with ketones, halogens, alkoxy or amines to tune the optoelectronic response. Due to all-sp ${ }^{2}$ carbons and rigid $\pi$-extended planar backbone, PAH shows higher absorption in the visible region, good thermal and chemical stability that allows it to be exploited as semiconducting materials. It also has a narrow highest occupied molecular orbital (HOMO) lowest unoccupied molecular orbital (LUMO) band alignment that can improve charge transport. DBP (Dibenzo $\left\{\left[\mathrm{f}, \mathrm{f}^{\prime}\right]-4,4^{\prime}, 7,7^{\prime}-\right.$ tetraphenyl $\}$ diindeno[1,2,3-cd:1',2',3'-lm]) is a known polyaromatic hydrocarbons based compound that has favorable known electrochemical and photo-physical properties [26]. It has been reported as dopants for emitter in OLEDs, applications in 
electrogenerated chemiluminescence (ECL) and as a donor material in both bulk and bilayer heterojunction organic solar cell fabrication [27-32]. We have also reported DBP as an electron donor with $\mathrm{C}_{70}$ as a bilayer in a planar heterojunction organic solar cell with a performance of 5.66\% [33]. Here we report our preliminary results on the fabrication of $\mathrm{MAPbBr}_{3}, \mathrm{FAPbBr}_{3}$ and $\left(\mathrm{FAPbI}_{3}\right)_{0.85}\left(\mathrm{MAPbBr}_{3}\right)_{0.15}$ based PSCs employing DBP as a hole transporting layer deposited in solution.

\section{Experimental}

\section{Materials}

The chemicals were bought from Sigma Aldrich, whereas 2,2',7,7'-tetrakis( $N, N$-di- $p$ methoxyphenylamine)-9,9-spirobifluorene (Spiro-OMeTAD) was acquired from Merck KGaA, methylammonium iodide (MAI), formamidinium iodide (FAI), methylammonium bromide (MABr) from Dyesol, $\mathrm{PbI}_{2}$ and $\mathrm{PbBr}_{2}$ were purchased from Tokyo Chemical Industry (TCI); all the chemicals were employed without any treatment or purification. DBP was procured from LumTec (Luminescence Technology Corp., Taiwan).

\section{Device fabrication}

The fluorine doped tin oxide (FTO) coated glasses (TEC15) was used as electrode and were cleaned prior to use, firstly by ultrasonication ( $2 \%$ Hellmanex water solution for 30 minutes) followed by rinsing with deionized water; acetone and isopropanol sequentially and finally heated up to $500{ }^{\circ} \mathrm{C}$ for the removal of any organic residue. $\mathrm{TiO}_{2}$ compact layer was deposited on cleaned FTO substrate via spray pyrolysis at $450{ }^{\circ} \mathrm{C}$ using a precursor solution of titanium diisopropoxide bis(acetylacetonate) in anhydrous ethanol. After the spraying, the substrates were left at $450{ }^{\circ} \mathrm{C}$ for 30 minutes and left to cool down to acquire room temperature. Followed by this, a $100-150$ 
nm of mesoporous $\mathrm{TiO}_{2}$ layer was deposited by spin coating process, for this a (1:8) $\mathrm{TiO}_{2}$ paste (Dyesol 30 NR-D) diluted in ethanol for $20 \mathrm{~s}$ at $4000 \mathrm{rpm}$ was used. The substrates were dried at $125^{\circ} \mathrm{C}$ and then annealed at $250{ }^{\circ} \mathrm{C}$ for $10 \mathrm{~min}, 350{ }^{\circ} \mathrm{C}$ for $10 \mathrm{~min}, 450{ }^{\circ} \mathrm{C}$ for $10 \mathrm{~min}$ in a fourstep temperature ramp and finally maintained at $500{ }^{\circ} \mathrm{C}$ for 30 min to allow transformation of amorphous $\mathrm{TiO}_{2}$ into anatase. When room temperature is attained, the substrates were transferred to an argon-filled glove-box for perovskite layer deposition. The precursor solution for preparing the mixed perovskite was prepared by dissolving FAI (1 M), $\mathrm{PbI}_{2}(1.2 \mathrm{M}), \mathrm{MABr}(0.2 \mathrm{M})$, and $\operatorname{PbBr}_{2}(0.2 \mathrm{M})$ in anhydrous DMF:DMSO 4:1 (v:v). The perovskite solution was spin coated in a two-step sequence at 1000 and $6000 \mathrm{rpm}$ for 10 and $20 \mathrm{~s}$, respectively. During the second step, $100 \mu \mathrm{L}$ of chlorobenzene was dripped as an antisolvent approach on the substrate $10 \mathrm{~s}$ prior the end of the spinning process. The perovskite coated substrates were annealed at $100{ }^{\circ} \mathrm{C}$ for $1 \mathrm{~h}$ in a glovebox. On acquiring room temperature, the hole transport layer was deposited. Spiro-OMeTAD (70 mM), or DBP (in three different concentrations: 10, 20 and $30 \mathrm{mM}$ ) was prepared by dissolving the corresponding amount of materials in chlorobenzene. Spiro-OMeTAD was doped by adding bis-(trifluoromethylsulfonyl)imide lithium salt (Li-TFSI), tris(2-(1H-pyrazol-1-yl)-4-tertbutylpyridine) cobalt(III)-tris(bis-(trifluoro-methylsulfonyl)imide) (FK209), and 4-tertButylpyridine $(t-\mathrm{BP})$ in the molar ratio $0.5,0.01$, and 3.3 respectively. DBP were doped by adding LiTFSI and $t$-BP as an additive in the molar ratio of 0.5 and 3.3 respectively. $35 \mu \mathrm{L}$ of HTM solutions were spin-coated atop of the perovskite layer at $4000 \mathrm{rmp}$ for $20 \mathrm{~s}$, in a dry air filled glove-box. To finish the device fabrication, gold layer of $70-80 \mathrm{~nm}$ as cathode was thermally evaporated under low vacuum $\left(10^{-6}\right.$ torr). All solutions were prepared inside an argon-filled glove box with controlled moisture and oxygen conditions $\left(\mathrm{O}_{2}<10 \mathrm{ppm}, \mathrm{H}_{2} \mathrm{O}<2 \mathrm{ppm}\right)$. 


\section{Device characterization}

The fabricated solar cells figure of merit was measured using current density-voltage $(J-V)$ curves, recorded with a Keithley 2400 source-measurement-unit under AM 1.5 G, $100 \mathrm{~mW} \mathrm{~cm}{ }^{2}$ illumination from a $450 \mathrm{~W}$ AAA solar simulator (ORIEL, 94023 A). NREL certified monocrystalline silicon solar cell was used for calibration. A black metal mask $\left(0.16 \mathrm{~cm}^{2}\right)$ was used over the square size active area $\left(0.5 \mathrm{~cm}^{2}\right)$ to reduce the influence of scattered light. Photovoltaic parameters including $J_{S C}, V_{O C}$, fill factor (FF), and power conversion efficiency (PCE) were extracted from the photocurrent-voltage $(J-V)$ curves of the solar cells (scan rate: 100 $\mathrm{mV} \mathrm{s}^{-1}$, pre-sweep delay: $10 \mathrm{~s}$ ). The IPCE measurements were performed using a Newport $150 \mathrm{~W}$ xenon lamp coupled to an Oriel Cornerstone 260 motorized 1/4 m monochromator as the light source, and a 2936-R power meter to measure the short circuit current.

\section{Result and Discussions}

The fabricated perovskite solar cells are depicted in Fig.S1 and bromide based high bandgap perovskites represents the semi-transparent nature. Figure 1a represents the band alignment and the relative energy levels of all the materials used in the present work. The calculated conductivity of undoped DBP was found to be $1.2 \times 10^{-6} \mathrm{~S} / \mathrm{cm}$ (Fig. S2). The DBP (structure depicted in Fig.1b) based hole transport layers (HTLs) possess a HOMO level of -5.5 and has favorable energy level match with $\mathrm{MAPbBr}_{3}$ or $\mathrm{FAPbBr}_{3}$, with $\mathrm{HOMO}$ levels of $-5.68 \mathrm{eV}$ and $-5.6 \mathrm{eV}$. The PSCs were fabricated using DBP as HTL, in a conventional mesoporous architecture such as FTO/c$\mathrm{TiO}_{2} /$ meso- $\mathrm{TiO}_{2} /$ perovskites/HTM/Au. The thickness of the DBP layer was optimized using three different concentrations, $10 \mathrm{mM}, 20 \mathrm{mM}$ and $30 \mathrm{mM}$, respectively. To elucidate the device architecture used as well as the morphology and microstructure of the perovskite film, scanning electron microscopy experiments were conducted. The cross-sectional image of a working device 
is represented in Fig. 1 and demonstrates interconnected and well-defined layers. In this case the perovskite active layer is the thickest layer, while the HTM layer is buried (due to very low thickness) between the perovskite and gold layer. A thin and compact mesoporous $\mathrm{TiO}_{2}$ layer is revealed in the SEM image. In a typical fabricated solar cells, the thickness measured from the cross sectional SEM image, the layers were calculated as c- $\mathrm{TiO}_{2} \sim 50 \mathrm{~nm}$, meso- $\mathrm{TiO}_{2} 151 \mathrm{~nm}$, $\mathrm{MAPbBr}_{3} 312 \mathrm{~nm}$, DBP $63 \mathrm{~nm}$ and Au $71 \mathrm{~nm}$ respectively. DBP possesses several distinctive features that have been utilized as electron donor materials in organic solar cells [34]. DBP has a deep lying HOMO level of $-5.5 \mathrm{eV}$ and a LUMO level of $-3.5 \mathrm{eV}$, matching well to several electron acceptor materials, and it has a strong absorption wavelength in the visible region from $300-700$ $\mathrm{nm}$ [35]. Recently, it was also introduced to the perovskite device fabrication [36], where the hole transport properties of the molecule can also make it well-suited as an interlayer.

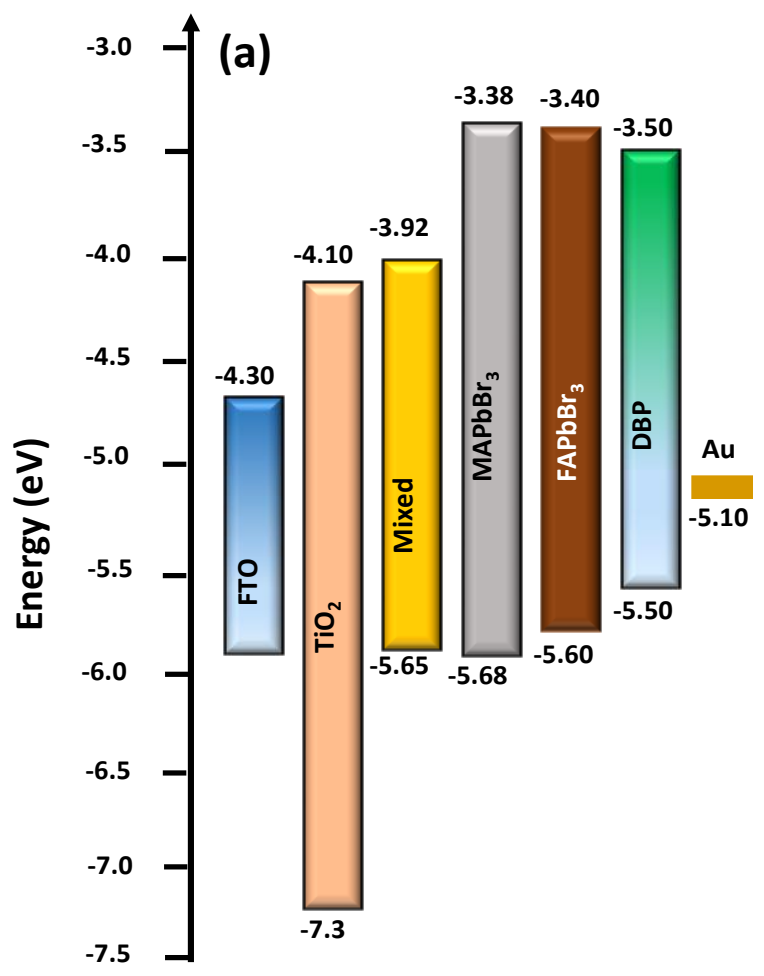

(b)

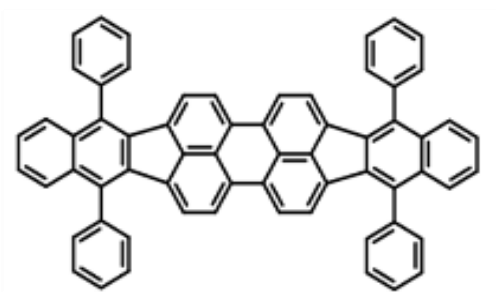

(c)

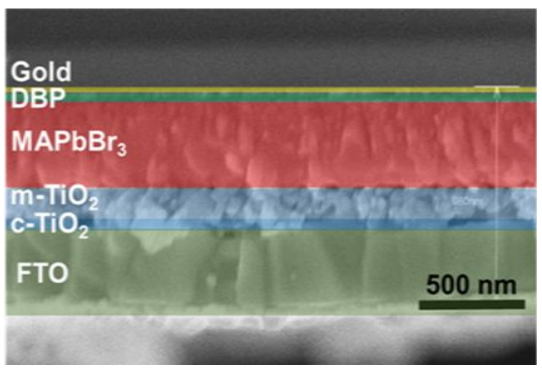

Fig.1: a) Energy level diagram of the fabricated perovskite solar cells, b) molecular structure of DBP and c) cross sectional diagram for the fabricated DBP based perovskite solar cells. 
The UV-vis absorbance spectra of the DBP in chlorobenzene (Fig. 2) shows the Soret bands around $500-600 \mathrm{~nm}$. Figure 2a shows the UV-visible absorption spectra of DBP films of different thickness, while $2 \mathrm{~b}$ shows UV-visible absorption spectra of DBP with the perovskite active layer. DBP exhibit multiple absorption peaks in the visible region at 521, 556, and $609 \mathrm{~nm}$ which is due to the $\pi-\pi^{*}$ transition in the conjugated system. A side shoulder peak appears at $480 \mathrm{~nm}$ representing minute absorption in the UV-region. The $\lambda_{\max }$ is at around $610 \mathrm{~nm}$. We note that the thicknesses investigated here has a smaller effect on the absorbance peak, while thinner films represents comparatively lower intensity.
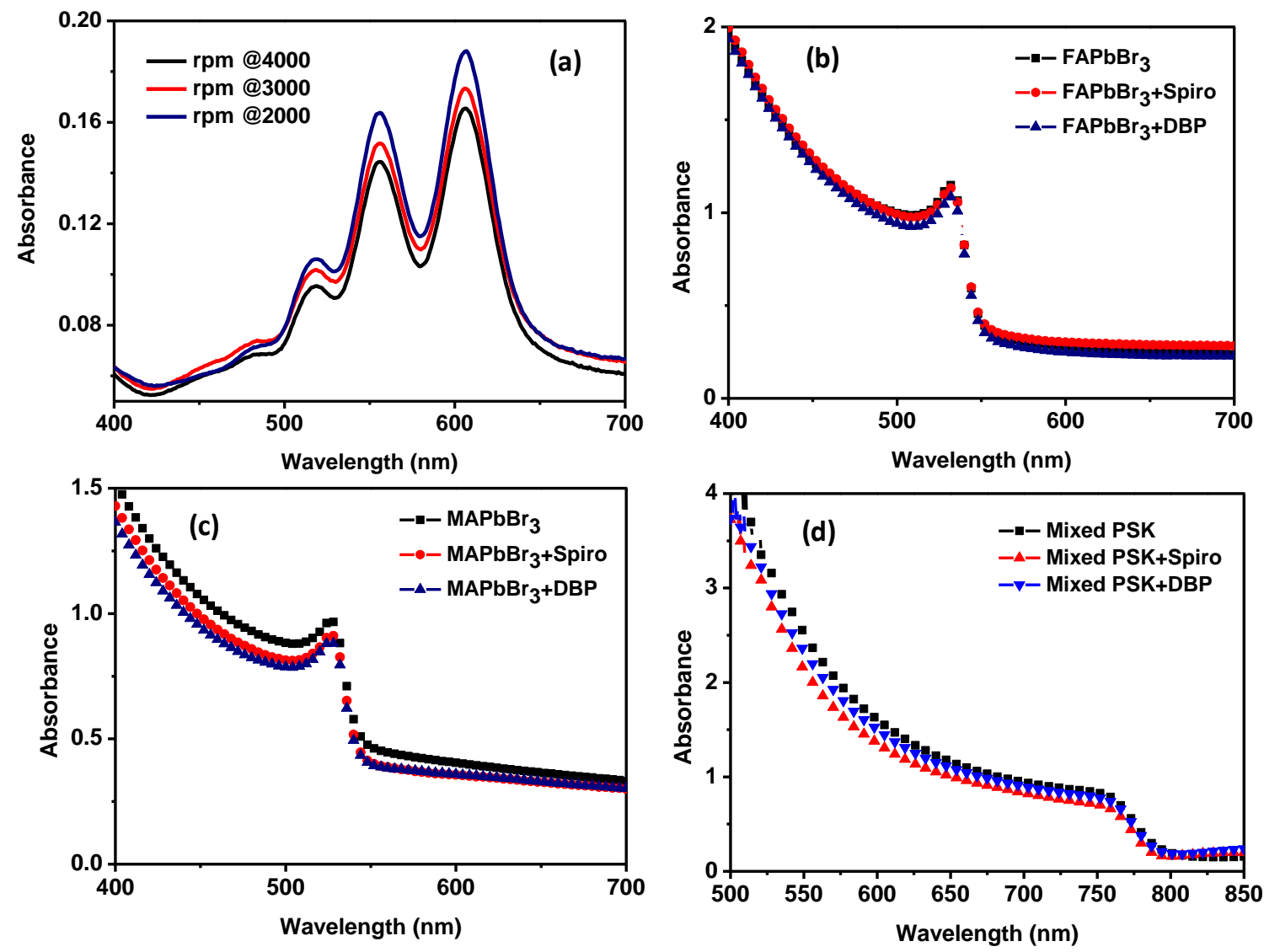

Fig. 2: UV-vis absorbance spectra for spin coated a) DBP layer at different speed (i.e. thickness), b) $\mathrm{FAPbBr}_{3}+\mathrm{HTM}$, c) $\mathrm{MAPbBr}_{3}+\mathrm{HTM}$ and d) $\left(\mathrm{FAPbI}_{3}\right)_{0.85}\left(\mathrm{MAPbBr}_{3}\right)_{0.15}+\mathrm{HTM}$. 

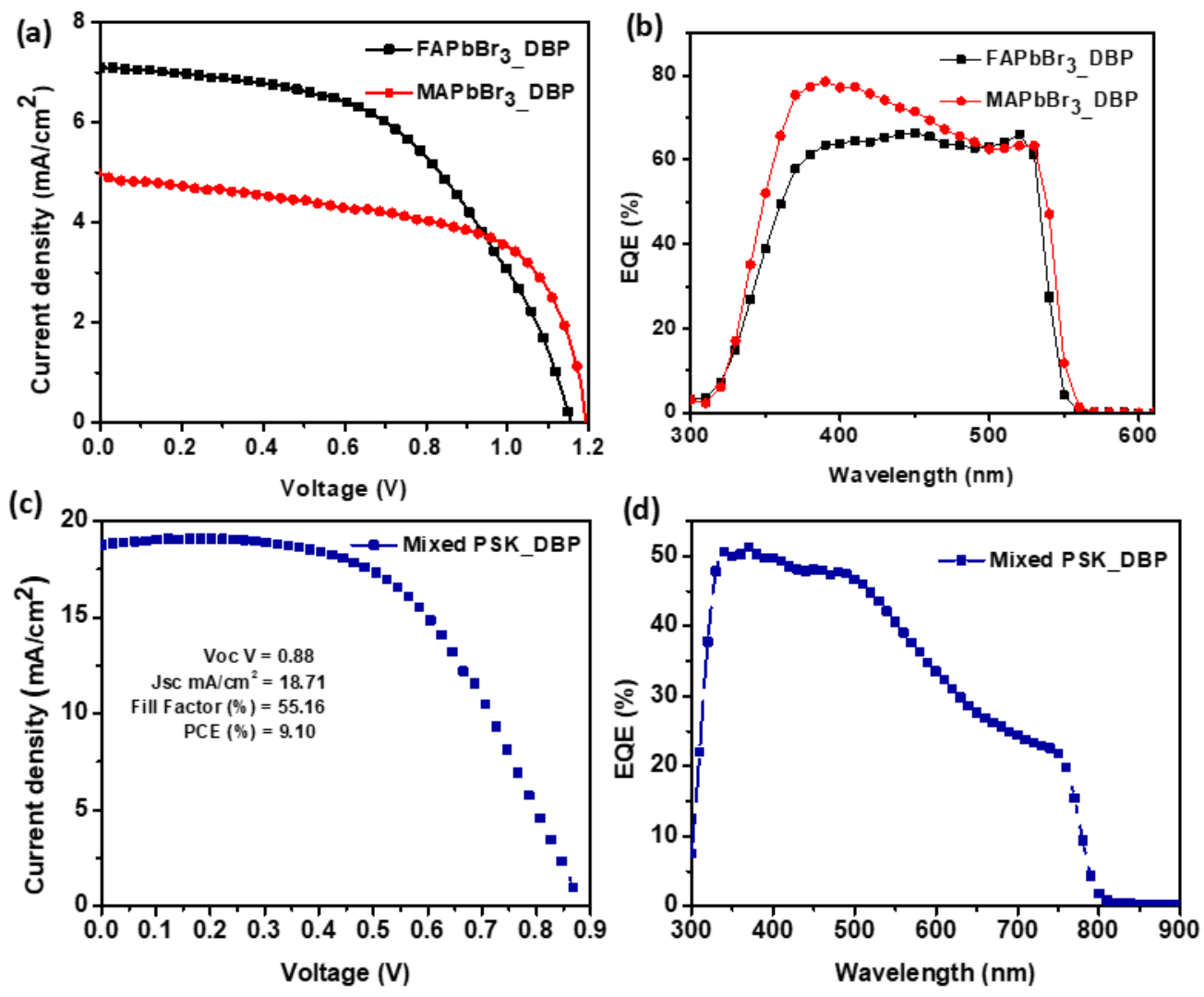

Fig. 3: (a) $J-V$ curve for the DBP based perovskite solar cells with $\mathrm{FAPbBr}_{3}$ and $\mathrm{MAPbBr}_{3}$, (b) incident photon-to-current efficiency of the DBP based perovskite solar cells with $\mathrm{FAPbBr}_{3}$ and $\mathrm{MAPbBr}_{3}$, (c) $J-V$ curve for the $\mathrm{DBP}$ with mixed perovskites i.e. $\left(\mathrm{FAPbI}_{3}\right)_{0.85}\left(\mathrm{MAPbBr}_{3}\right)_{0.15}$ and (d) incident photon-to-current efficiency of the DBP with mixed perovskite.

For the figure of merit calcualtion of the fabricated PV devices, the $J-V$ curves were recorded under 1 sun simulated air mass 1.5 global (AM1.5G) sunlight. Figure 3 illustrates the $J$ - $V$ characteristics under illumination at $100 \mathrm{~mW} / \mathrm{cm}^{2}$ for the devices in reverse direction (From $V_{\text {oc }}$ to $J_{\text {sc }}$ ) at 100 $\mathrm{mV} / \mathrm{s}$. Table 1 summarizes the average $\mathrm{PV}$ parameters with the value of series resistance and shunt resistance. 

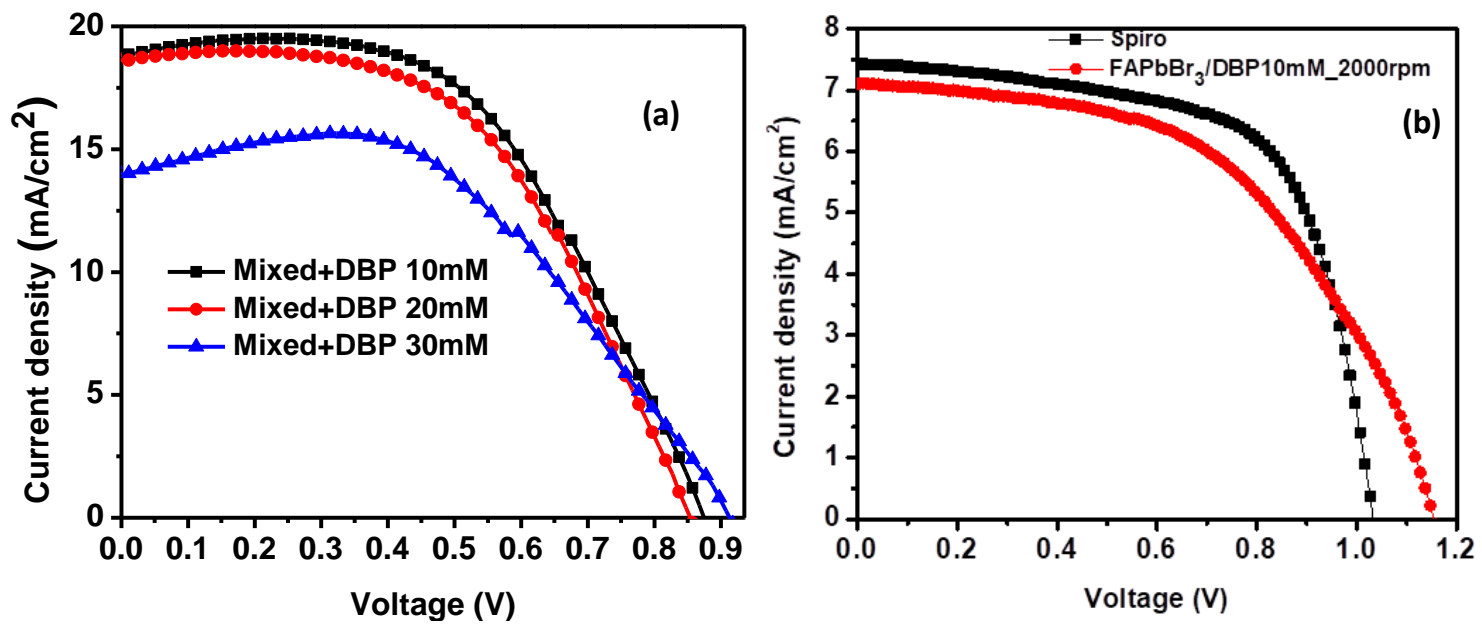

Fig. 4: a) Effect of DBP thickness, $J-V$ curve for the mixed perovskite solar cells with different thickness of DBP and (b) for comparative purpose, $\mathrm{FAPbBr}_{3}$ based perovskite solar cells with 10mM DBP and standard (70mM) Spiro-OMeTAD.

The increase in short circuit current density $\left(J_{\mathrm{sc}}\right)$ with the usage of mixed perovskites was expected due to shifting of absorption onset to longer wavelength. The average $J_{\mathrm{sc}}$ and fill factor (FF) increased gradually from to $18.71 \mathrm{mAcm}^{-2}$ and $55.17 \%$. The lowest value for $J_{\mathrm{sc}}$ was observed for $\mathrm{MAPbBr}_{3}$, which is in-line with the optical absorption of these two perovskite active layers (Figure 2). A drop in $V_{\text {oc }}$ was noted with respect to $\operatorname{MAPbBr}_{3}\left(V_{o c}=1152 \mathrm{mV}\right)$ for the mixed perovskites $\left(V_{o c}=880 \mathrm{mV}\right)$ due to a reduced band gap, which is in accordance with previous results. A relativley lower FF was observed in case of mixed perovskites, due to unbalance charge extraction causing increase series resistance in the PV performance. It can be deduced from the Figure 3 that there is an improvement in the average PCE in the case of mixed perovskite as compared to pure bromide based perovksites, due to panchromatic light harvesting. We noted that thinner layers of DBP $(10 \mathrm{mM})$ worked effectively for the bromide based high band gap perovskite cells as compared to Spiro-OMeTAD (Fig. S3). By reducing the concentrations of DBP, thinner HTLs can be formed, which shows improved device performance. We speculate that this is due to 
a decrease in series resistance and from that more effective charge extraction. In general the open circuit voltages for the $\mathrm{MAPbBr}_{3}$ cells were high $>1150 \mathrm{mV}$, due to the use of high bandgap perovskites. The performance limiting parameter was the short circuit current, which was low due to the use of $\mathrm{MAPbBr}_{3}$ as active layers (limited absorption, Figure 2), while the FF close to 0.6 was obtained. In the case of mixed perovskites, higher current values were noted with an PCE value $>9.1 \%$. The incident photon-to-current efficiency (IPCE) measurement region was recorded in the wavelength range of $300-850 \mathrm{~nm}$, where the active layer shows photoconversion. In agreement with the absorbance experiments, the formamidinium cation based solar cells resulted in shifting of IPCE onset towards red part of the spectrum. For $\mathrm{FAPbBr}_{3}$, approx. $60 \%$ light to electricity conversion can be observed in the visible part of the spectra. This indicates that excitons and/or free charges were effectively generated in the perovskite layers upon light illumination.

Table1 : Device PV parmeters for the fabricated solar cells

\begin{tabular}{|c|c|c|c|c|c|c|c|}
\hline Sample & Voc $(\mathrm{mV})$ & $\begin{array}{l}J \mathbf{s c} \\
\left(\mathrm{mA} / \mathrm{cm}^{2}\right)\end{array}$ & $\begin{array}{l}\text { FF } \\
(\%)\end{array}$ & $\begin{array}{l}\text { PCE } \\
(\%)\end{array}$ & $\begin{array}{l}\text { Avg. } \\
\text { PCE(\%) }\end{array}$ & $\boldsymbol{R}_{\mathrm{s}}$ & $\boldsymbol{R}_{\text {shunt }}$ \\
\hline $\mathrm{FAPbBr}_{3} / \mathrm{DBP}$ & $\begin{array}{l}1150 \\
( \pm 0.06)\end{array}$ & $\begin{array}{l}7.10 \\
( \pm 0.28)\end{array}$ & $\begin{array}{l}52.29 \\
( \pm 3.45)\end{array}$ & $\begin{array}{l}4.28 \\
( \pm 0.16)\end{array}$ & 4.12 & 209.746 & 9431.38 \\
\hline $\mathrm{MAPbBr}_{3} / \mathrm{DBP}$ & $\begin{array}{l}1190 \\
( \pm 0.21)\end{array}$ & $\begin{array}{l}4.95 \\
( \pm 2.01)\end{array}$ & $\begin{array}{l}59.96 \\
( \pm 7.33)\end{array}$ & $\begin{array}{l}3.54 \\
( \pm 0.22)\end{array}$ & 3.31 & 112.92 & 5631.92 \\
\hline Mixed/DBP & $\begin{array}{l}880 \\
( \pm 0.02)\end{array}$ & $\begin{array}{l}18.71 \\
( \pm 0.27)\end{array}$ & $\begin{array}{l}55.17 \\
( \pm 1.02)\end{array}$ & $\begin{array}{l}9.10 \\
( \pm 0.07)\end{array}$ & 9.02 & 69.784 & 189598 \\
\hline $\mathrm{FAPbBr}_{3} /$ Spiro & $\begin{array}{l}1000 \\
( \pm 0.11)\end{array}$ & $\begin{array}{l}7.44 \\
( \pm 0.88)\end{array}$ & $\begin{array}{l}70.26 \\
( \pm 4.07)\end{array}$ & $\begin{array}{l}5.24 \\
( \pm 0.35)\end{array}$ & 4.89 & 94.85 & 33519 \\
\hline $\mathbf{M A P b B r}_{3} /$ Spiro & $\begin{array}{l}1250 \\
( \pm 0.27)\end{array}$ & $\begin{array}{l}5.73 \\
( \pm 1.57)\end{array}$ & $\begin{array}{l}62.60 \\
( \pm 5.31)\end{array}$ & $\begin{array}{l}4.50 \\
( \pm 1.38)\end{array}$ & 3.12 & 125.40 & 9667 \\
\hline Mixed/Spiro & $\begin{array}{l}987 \\
( \pm 0.04)\end{array}$ & $\begin{array}{l}20.50 \\
( \pm 0.19)\end{array}$ & $\begin{array}{l}66.38 \\
( \pm 3.08\end{array}$ & $\begin{array}{l}13.50 \\
( \pm 0.39)\end{array}$ & 13.11 & 38.63 & 5753.87 \\
\hline
\end{tabular}


Though promising photovoltaic performances were obtained, from optimizing the thickness of HTL, the reported PCE are relatively lower. In particular, the relatively low $F F$ of the DBP based devices could be due to the relatively lower hole transport ability of these materials, supported by the presence of high series resistance. Thus, by reducing the concentration of the DBP precursor solutions and correspondingly the HTL thickness, we could partially mitigate that problem. The reduced charge carrier mobility are partly due to the molecular packing in the film formation, originating due to the steric hindrance of the bulky substituents on the polyaromatic moiety. The open circuit voltage relatively remains constant, on reducing the thickness of HTL, as the mismatch in the energetic levels of these new molecules with the perovskites is relatively low.

\section{Conclusions:}

To summarized, we presented the usage of DBP (Dibenzo $\left\{\left[f, f^{\prime}\right.\right.$ ]-4,4',7,7'tetraphenyl $\}$ diindeno[1,2,3-cd :1',2',3'-lm ]perylene, highly soluble in common organic solvents. DBP was used as a hole transport layer utilizing solution process route, for the fabrication perovskite solar cells fabrication and efficiency in excess of $9 \%$ was achieved. The thickness of DBP as hole selective layer was optimized by concentration tweaking, we noted the device performance can be enhanced by using thin DBP layers. The DBP based hole transport layer gave competitive power conversion efficiencies once optimized, signaling potential use of DBP as hole transport layer for high bandgap perovskites. Semi-transparent solar cells that require the usage of transparent and effective light-harvesters have the added advantage of being used in BIPV due to its aesthetic benefits were also fabricated utilizing high band gap perovskites. The presented results will imply the research direction for fabricating efficient semi-transparent solar cells.

\section{Conflict of Interests}

The authors declare no competing interests. 


\section{Acknowledgements}

This work has received funding from the European Union H2020 Programme under European Research council Consolidator grant [MOLEMAT, 726360] and Thinface (FP7).

\section{References}

1. M. M. Lee, J. Teuscher, T. Miyasaka, T. N. Murakami, H. J. Snaith, Efficient hybrid solar cells based on meso-superstructured organometal halide perovskites. Science 338(6107), 643 (2012).

2. M. R. Filip, G. E. Eperon, H. J. Snaith, F. Giustino, Steric engineering of metal-halide perovskites with tunable optical band gaps. Nat. Commun. 5(5757) (2014).

3. H. J. Snaith, Perovskites: the emergence of a new era for low-cost, high-efficiency solar cells. J. Phys. Chem. Lett. 4(21), 3623 (2013).

4. H.-S. Kim, C.-R. Lee, J.-H. Im, K.-B. Lee, T. Moehl, A. Marchioro, S.-J. Moon, R. HumphryBaker, J.-H. Yum, J. E. Moser, Lead iodide perovskite sensitized all-solid-state submicron thin film mesoscopic solar cell with efficiency exceeding 9\%. Sci. Rep. 2591 (2012).

5. D. B. Mitzi, C. Field, W. Harrison, A. Guloy, Conducting tin halides with a layered organicbased perovskite structure. Nature. 369(6480), 467 (1994).

6. K.-L. Wu, A. Kogo, N. Sakai, M. Ikegami, T. Miyasaka, High efficiency and robust performance of organo lead perovskite solar cells with large grain absorbers prepared in ambient air conditions. Chem. Lett. 44(3), 321 (2014).

7. K. A. Bush, A. F. Palmstrom, J. Y. Zhengshan, M. Boccard, R. Cheacharoen, J. P. Mailoa, D. P. Mcmeekin, R. L. Hoye, C. D. Bailie, T. Leijtens, 23.6\%-efficient monolithic perovskite/silicon tandem solar cells with improved stability. Nature Energy. 2(4), 17009 (2017).

8. F. Sahli, J. Werner, B. A. Kamino, M. Bräuninger, R. Monnard, B. Paviet-Salomon, L. Barraud, L. Ding, J. J. D. Leon, D. Sacchetto, Fully textured monolithic perovskite/silicon tandem solar cells with 25.2\% power conversion efficiency. Nat. Mater. 17(9), 820 (2018).

9. G. Niu, X. Guo, L. Wang, Review of recent progress in chemical stability of perovskite solar cells. J. Mater. Chem. A. 3(17), 8970 (2015).

10. K. Rakstys, C. Igci, M. K. Nazeeruddin, Efficiency vs. stability: dopant-free hole transporting materials towards stabilized perovskite solar cells. Chem. Sci., 10, 6748-6769 (2019).

11. M. Jung, T. J. Shin, J. Seo, G. Kim, S. I. Seok, Structural features and their functions in surfactant-armoured methylammonium lead iodide perovskites for highly efficient and stable solar cells. Energy Environ. Sci. 11(8), 2188 (2018); F. Khan, J. H. Ki, Enhanced charge-transportation properties of low-temperature processed Al-doped $\mathrm{ZnO}$ and its impact on PV cell parameters of organic-inorganic perovskitesolarcells. Solid State Electron. 164, 107714 (2020)

12. L. Calió, C. Momblona, L. Gil-Escrig, S. Kazim, M. Sessolo, Á. Sastre-Santos, H. J. Bolink, S. Ahmad, Vacuum deposited perovskite solar cells employing dopant-free triazatruxene as the hole transport material. Sol. Energy Mater. Sol. Cells. 163(237) (2017).

13. E. Edri, S. Kirmayer, D. Cahen, G. Hodes, High open-circuit voltage solar cells based on organic-inorganic lead bromide perovskite. J. Phys. Chem. Lett. 4(6), 897 (2013).

14. S. Ryu, J. H. Noh, N. J. Jeon, Y. C. Kim, W. S. Yang, J. Seo, S. I. Seok, Voltage output of efficient perovskite solar cells with high open-circuit voltage and fill factor. Energy Environ. Sci. 7(8), 2614 (2014). 
15. J. H. Heo, D. H. Song, S. H. Im, Planar $\mathrm{CH}_{3} \mathrm{NH}_{3} \mathrm{PbBr}_{3}$ hybrid solar cells with $10.4 \%$ power conversion efficiency, fabricated by controlled crystallization in the spin-coating process. Adv. Mater. 26(48), 8179 (2014).

16. B.-W. Park, B. Philippe, T. R. Gustafsson, K. R. SveinbjöRnsson, A. Hagfeldt, E. M. Johansson, G. Boschloo, Enhanced crystallinity in organic-inorganic lead halide perovskites on mesoporous $\mathrm{TiO}_{2}$ via disorder-order phase transition. Chem. Mater. 26(15), 4466 (2014).

17. M. Liu, M. B. Johnston, H. J. Snaith, Efficient planar heterojunction perovskite solar cells by vapour deposition. Nature. 501(7467), 395 (2013).

18. G. E. Eperon, S. D. Stranks, C. Menelaou, M. B. Johnston, L. M. Herz, H. J. Snaith, Formamidinium lead trihalide: a broadly tunable perovskite for efficient planar heterojunction solar cells. Energy Environ. Sci. 7(3), 982 (2014).

19. F. C. Hanusch, E. Wiesenmayer, E. Mankel, A. Binek, P. Angloher, C. Fraunhofer, N. Giesbrecht, J. M. Feckl, W. Jaegermann, D. Johrendt, Efficient planar heterojunction perovskite solar cells based on formamidinium lead bromide. J. Phys. Chem. Lett. 5(16), 2791 (2014).

20. Y. Zhang, Y. Liang, Y. Wang, F. Guo, L. Sun, D. Xu, Planar FAPbBr 3 Solar Cells with Power Conversion Efficiency above 10\%. ACS Energy Lett. 3(8), 1808 (2018).

21. N. Arora, M. I. Dar, M. Abdi-Jalebi, F. Giordano, N. Pellet, G. Jacopin, R. H. Friend, S. M. Zakeeruddin, M. Grätzel, Intrinsic and extrinsic stability of formamidinium lead bromide perovskite solar cells yielding high photovoltage. Nano Lett. 16(11), 7155 (2016).

22. G. E. Eperon, S. D. Stranks, C. Menelaou, M. B. Johnston, L. M. Herz, H. J. Snaith, Formamidinium lead trihalide: a broadly tunable perovskite for efficient planar heterojunction solar cells. Energy Environ. Sci. 7(3), 982 (2014).

23. P. Herwig, C. W. Kayser, K. Müllen, H. W. Spiess, Columnar mesophases of alkylated hexaperi-hexabenzocoronenes with remarkably large phase widths. Adv. Mater. 8(6), 510 (1996).

24. A. Fechtenkötter, K. Saalwächter, M. A. Harbison, K. Müllen, H. W. Spiess, Highly Ordered Columnar Structures from Hexa-peri-hexabenzocoronenes-Synthesis, X-ray Diffraction, and Solid-State Heteronuclear Multiple-Quantum NMR Investigations. Angew. Chem. 38(20), 3039 (1999).

25. J. Wu, W. Pisula, K. Müllen, Graphenes as potential material for electronics. Chem. Rev. 107(3), 718 (2007).

26. J. D. Debad, J. C. Morris, V. Lynch, P. Magnus, A. J. Bard, Dibenzotetraphenylperiflanthene: synthesis, photophysical properties, and electrogenerated chemiluminescence. J. Am. Chem. Soc. 118(10), 2374 (1996).

27. A. N. Bartynski, S. Grob, T. Linderl, M. Gruber, W. Brütting, M. E. Thompson, Organic Solar Cells with Open Circuit Voltage over 1.25 V Employing Tetraphenyldibenzoperiflanthene as the Acceptor. J. Phys. Chem. C. 120(34), 19027 (2016).

28. B. R. Patil, Y. Liu, T. Qamar, H.-G. Rubahn; M. Madsen, 4P-NPD ultra-thin films as efficient exciton blocking layers in DBP/C70 based organic solar cells. J. Phys. D. 50(38), 385101 (2017). 29. M. Ahmadpour, A. L. Fernandes Cauduro, C. Méthivier, B. Kunert, C. Labanti, R. Resel, V. Turkovic, H.-G. Rubahn, N. Witkowski, A. K. Schmid, Crystalline molybdenum oxide layers as efficient and stable hole contacts in organic photovoltaic devices. ACS Appl. Energy Mater. 2(1), 420 (2018).

30. M. Ahmadpour, Y. Liu, H.-G. Rubahn, M. Madsen, Current matching in multifold DBP/C70 organic solar cells with open-circuit voltages of up to 6.44 V. IEEE J. Photovolt. 7(5), 1319 (2017). 
31. G. Sherafatipour, J. Benduhn, B. R. Patil, M. Ahmadpour, D. Spoltore, H.-G. Rubahn, K. Vandewal, M. Madsen, Degradation pathways in standard and inverted DBP-C70 based organic solar cells. Sci. Rep. 9(1), 4024 (2019).

32. X. Che, Y. Li, Y. Qu, S. R. Forrest, High fabrication yield organic tandem photovoltaics combining vacuum-and solution-processed subcells with $15 \%$ efficiency. Nat. Energy. 3(5), 422 (2018).

33. L. Caliò, B. R. Patil, J. Benduhn, K. Vandewal, H.-G. Rubahn, M. Madsen, S. Kazim, S. Ahmad, Benzothiadiazole-triphenylamine as an efficient exciton blocking layer in small molecule based organic solar cells. Sustain. Energy Fuels. 2(10), 2296 (2018).

34. N. Cheng, Y. Peng, T. L. Andrew, Origin of high open-circuit voltage in a planar heterojunction solar cell containing a non-fullerene acceptor. Appl. Phys. Lett. 111(13), 133901 (2017).

35. R. Marczyński, J. Szostak, R. Signerski, G. Jarosz, Photovoltaic effect in the single-junction DBP/PTCBI organic system under low intensity of monochromatic light. Curr. Appl. Phys. 19(11), 1271 (2019).

36. S. Ding, S. Li, Q. Sun, Y. Wu, Y. Liu, Z. Li, Y. Cui, H. Wang, Y. Hao, Y. Wu, Enhanced performance of perovskite solar cells by the incorporation of the luminescent small molecule DBP: perovskite absorption spectrum modification and interface engineering. J. Mater. Chem. C. 7, 5686-5694 (2019). 